\title{
Multi-Response Optimization Of Process Parameter in Vertical Milling Machine Of EN31 Using Taguchi Method
}

\author{
"Sunil Kumar", Dr.P.Sudhakar.Rao" " \\ 1. M.E. Scholar, Department of Mechanical Engineering, National Institute of Technical Teachers Training and \\ Research (NITTTR), Chandigarh (India). \\ 2. Assistant Professor, Department of Mechanical Engineering, National Institute of Technical Teachers Training \\ and Research (NITTTR), Chandigarh (India). \\ "Mechanical Engineering Department, NITTTR, Chandigarh-160019, India"
}

\begin{abstract}
The purpose of this experimental research is to compare the effectiveness of using the Taguchi approach for the multi-response optimization of process parameters in Vertical Milling Machine of EN31 Material intending to minimize the surface roughness and tool wear rate while maximizing material removal rate to improve the productivity of the process with coated carbide insert. Taguchi L9 and Annova have been applied for the experimental design and analysis. This experiment shows that feed and depth of cut are the factors that are important for the tool wear. Depth of cut is a factor responsible for the Material Removal Rate and Feed is the most notable factor for surface roughness. Spindle speed has little effect on tool wear rate, surface roughness and material removal rate. Mathematical models for three response parameters i.e. tool wear rate, surface roughness, and material removal rate were obtained by the regression analysis method.
\end{abstract}

Keywords:CNC Milling Taguchi, Anova, Optimisation

\section{Introduction}

EN31 is the common material used where lightweight and corrosion resistance is required. EN31 is commonly used in the aerospace and automobile industry for manufacturing of shafts, wheels, bumpers, cylinder blocks, piping brake components, wings, etc.The vertical Milling machine has many input process parameters such as spindle speed, feed, depth of cut, etc.which affects the output responses such as surface roughness,Material Removal Rate and Tool Wear Rate.Optimization of input process parameters leads to producing good quality components at a lower cost. However, various techniques such as Taguchi design, Response Surface Methodology, Grey Relational Analysis, etc. are available in the literature for the design of experiments and optimization.

Deepak, D. and Beeduet al. [1] discussed the different parameters by which material removal rate and surface roughness can be optimised for turning process. CNC Turning machine using tungsten carbide(TC) tool and SE-40 coolant for this purpose \& hence evolutionary optimization techniques like Grey Relational Analysis (GRA) and Taguchi's L9 array base optimization techniques were performed for optimising the parameters. M. Kaladhar et al. [2] suggested the optimization of surface roughness (Ra) for Turning Process of Austenitic Stainless-Steel AISI202. CNC Turning machine using coated cemented carbide inserts for this purpose \& hence evolutionary analyse technique analysis of variance (ANOVA) technique wastaken into consideration for result parameters and there effects on roughness. It has been calculated that nose radius and feed are the vital parameters for roughness. Campatelli et al. [3] attempted to minimize power consumption in milling process of Carbon steel. CNC Milling machine using for this purpose \& analyse technique Response Surface Methodology (RSM) was used to obtain a model fit for the fine tuning of the process parameter. It is observed that if process parameters will be optimized then cutting energy to be maximize at local level.Vasudevan et al. [4] suggested regarding the optimizing the parameters of turning process of GFRP/Epoxy composites in reference to material removal rate (MRR) surface roughness (Ra). CNC Turning machine using for this purpose \& Grey Relational Analysis (GRA) Fuzzy Interface System (FIS) and Taguchi's orthogonal L27 optimization techniques were performed for optimising the parameters.In fuzzy rule- 

with Nano fluid. Conventional turning machine using for this purpose \& Response Surface Methodology (RSM) optimization technique was used for optimum parameter. Ithas been calculated that depth of cut and feed along with speed are the most significant parameter for the right quality. V. Jaiganesh et al. [6] suggested the optimization of material removal rate (MRR) chip thickness ratio (CTR) and surface roughness (SR) for turning process of mild steel. CNC turning machine using carbide tipped general purpose tool for this purpose \& Taguchi technique was used for optimising the parameters. Analysis of variance (ANOVA) used for analyse the optimum parameter. It is observed that MRR and CTR are directly proportional to each other. Jagannadha\& Kumar [7] Investigated the impact of machining parameter spindle speed, feed and depth of cut on material removal rate (MRR) and surface roughness (SR) for turning process of aluminium alloy 6063 and A380. CNC vertical Milling machine using for this purpose \& Taguchi technique was used for conducting the experiment. Analysis of variance (ANOVA) used for analyse the optimum parameters. Yubin Lee et al. [8] suggested to optimization of parameter MRR and SR for milling process for different material. CNC Milling machine using for this purpose \&Nelder-Mead Simplex Method used for optimized the parameter. It is observed that when the Nelder-Mead simplex method employed the profit was higher than the maximum profit obtained. M. Azuddin\& W. Abdullah [9] studied on surface roughness and burr formation for End Milling cutter of $\mathrm{Al}$ 6061. CNC milling machine using carbide cutting tool for this purpose. The test was repeated 5 times to get the desired results. It is studied that in small slot milling operations the input parameters will impacts the roughness very much and also burrs formation. JijuAnatony [10] suggested the optimization of multi response in industrial experiment on case study. Taguchi's Quality Loss function and Principal Component Analysis (PCA) method used for optimization of different response system. It has been studied that minimum number of uncorrelated function can be achieved by taguchi's quality loss function and PCA.Mumtaz

Rizwee \&Dr. P. Sudhakar Rao[25] experimentation highlights the effect of process parameter on the machining responses in term of WR during the $\mathrm{EDM}$ of $\mathrm{Al} / \mathrm{B} 4 \mathrm{C} / \mathrm{Gr}$ metal matrix composite [16]. On increasing the TON time WR initially decreases upto $400 \mu \mathrm{sec}$ and after that start to increase. WR is first increases on increasing pulse current upto 4 ampere after that start to decrease. On increasing the percentage of reinforcement WR decreases.

Abhisheik Thakur, Younis Khan \& Dr. P. Sudhakar Rao[26] discussed machining of Ti-6246 was carried out on EDM using graphite electrode using EDM oil dielectric. The process variables selected were current, pulse ontime and pulse off-time. Design of experiment was based on Box-Behnken Design of RSM technique. Optimization was conducted through desirability approach. Machinability of Ti-6246 work material was evaluated with regards to surface roughness, as better surface quality is requirement for every machined component.The optimized response parameter achieved was surface roughness of $0.99 \mathrm{~mm}$. Confirmation test were conducted at optimized variables and the value of surface roughness of $1.01 \mathrm{~mm}$ was obtained. Values obtained by multi-response.Dr P. Sudhakar Rao,P.K.Jain \& D.K.Dwivedi [27] discussed the ECH process can conclude that a very good improvement in average surface roughness Ra about $79.45 \%$ at top portion of the cylindrical work piece, $85.94 \%$ atmiddle portion of the cylindrical work piece and $79.07 \%$ at bottom portion of the cylindrical work piece respectively at 8 minutes of Finishing Time. Nishant Verma, S C Vettivel,Dr P.S Rao and Sunny Zafar [28] discussed the analysis and optimization of the experimental results were carried out using response surface methodology. The feed rate was considered as the most influencing parameter for SR and MRR. Speed was considered as the most influencing factor for tool wear and the wt\% of reinforcement is considered as least influencing factor for MRR. Rahul Bansal, Dr .P Sudhakar Rao, Amritbir Singh[29] suggested that face milling of Incoloy 800 was accomplished with Titanium coated cryogenic treated tungsten carbide inserts to optimize the input process variables viz. $\mathrm{Vc}, \mathrm{f}$ and $\mathrm{d}$ for optimum Tw and Ra. The three level BBD was employed for developing mathematical models for calculating the optimized values of Ra and Tw. Nishant Kumar, P. Sudhakar Rao[30] Machining Is Greatly Influenced By MRR, TWR And SR. Therefore, Pulse On Time, Voltage, Current And Type Of International Journal Of Scientific \& Technology Research Volume 9, Issue 02, February 2020 Issn 2277-8616 6005 Ijstr@2020 Www.Ijstr.Org Dielectric Medium Will Be Taken As Input Parameters For Optimization Purpose. Pulse On Time May Be Most Effective Parameter For Obtaining Maximum MRR. Type Of Dielectric Fluid May Influence Tool Wear Rate And Heat Removal. Current May affect the penetration power. Taguchi methodology may be adopted for process optimizationShweta. Verma \& P. Sudhakar Rao[31] discussed the materials used for wire drawing are stainless steel, high carbon steel, copper etc.Experiments have been conducted on various parameters like speed, temperature, friction, stress, force, area of reduction, die angle etc. Different methodologies have been used to improve surface finish of wire and optimization of process parameters. By optimization of process parameters, a better quality wire can be produced . Chandan Mattu, Dr. P. Sudhakar Rao [32] discussed the best suited method for synthesis of aluminium matrix composites is the stir casting as it is simple and cost effective. The mostly used apparatus for wear testing is the Pin-on-disc wear testing machine.The input parameters for wear testing are applied load, sliding distance and sliding speed. Shipra Verma, P.Sudhakar Rao [33] suggested that Stir casting method is best for adding reinforcement in order to avoid porosity, agglomerations and does not damage the reinforcement. The method of stir casting was successfully use to manufacture the $\mathrm{Al} 6061$ composite with proper allocationof particle in the Al matrix composite. The mechanical properties of composite material like compressive strength, hardness, tensile strength enhances because of adding various reinforcement like $\mathrm{B} 4 \mathrm{C}, \mathrm{SiC}, \mathrm{Al} 2 \mathrm{O}$, Bamboo leaf and Rice 
The literature review found that numerous researchers have used Taguchi design either in isolation or in combination with the ANOVA method for multi-response optimization of process parameters for minimization of surface roughness and maximizing MRR in the machining of different alloys. In this work, an effort was made to multiresponse optimization of process parameters in Vertical Milling Machine of EN31 to minimize Tool Wear Rate while maximizing Material Removal Rate to improve the productivity of the process.

\section{Material \& Experimentation}

It is important to select the output parameters of interest for specific practical application. Output parameters are process dependent variables. In this paper surface roughness and material removal rate (MRR) have been chosen as output variables. These variables are conflicting in nature as maximization of MRR is sought for and optimum value of Surface roughness is also aimed.

Surface roughness: Surface roughness defines how much a surface on the component varies from ideal flat plane or reference plane constructed by least squares method. Coordinate measuring machines are best equipped to measure Surface roughness.

Material Removal Rate (MRR): Material removal rate is defined as rate of material removal per unit time. It is measured by taking the weight of part before and after machining and using the following equation.

D: Depth of cut, mm.

W: Width of cut, mm.

F: Feed rate, $\mathrm{mm} / \mathrm{min}$

$\mathrm{MRR}=(\mathrm{D} \times \mathrm{W} \times \mathrm{F} / 1000) \mathrm{cc} / \mathrm{min}$

Tool Wear Rate (TWR): Tool wear rate is defined as rate of tool material removal per unit time.TWR is calculated by measuring the weight of the tool before and after machining

The input variables are independent of process and they are assumed to have influence on the output variables. The following input variables are selected for this research work are as follows:

Cutting Speed (V): Cutting speed is defined as the linear speed in $\mathrm{m} / \mathrm{min}$ of given tooth of a cutter will be moving while cutting operation takes place.

Where ' $\mathrm{D}$ ' is in 'metre' and ' $\mathrm{N}$ ' is in 'r.p.m'.

Feed Rate (F): Feed rate is the relative velocity at which the cutter advances during specific movement of the work piece. The range of feed rate is taken from $50 \mathrm{~mm} / \mathrm{min}$ to $150 \mathrm{~mm} / \mathrm{min}$.

Depth of Cut (d): It is cutting depth along Z-direction. The depth of cut used for this research work is measured in $\mathrm{mm}$ and the range taken in this research work is from $0.5 \mathrm{~mm}$ to $1.5 \mathrm{~mm}$.

The material, equipment and instruments used in the present work are discussed in this section appended below.

\subsection{EN31 Testing \& Confirmation}

EN31 material is selected to perform the machining process. 4 pieces of the length of $100 \mathrm{~mm}$ and breadth of 100 $\mathrm{mm}$ were taken for the machining purpose.Spectroscopy test was carried out on (Foundary-Master Xline)to confirm the composition of the material. The elemental composition obtained from the test is shown in Table 1.

Table 1. Chemical Composition of EN31

\begin{tabular}{|c|c|c|c|c|c|c|c|c|c|c|}
\hline Elements & $\mathbf{A l}$ & $\mathbf{C}$ & $\mathbf{S i}$ & $\mathbf{P}$ & $\mathbf{M n}$ & $\mathbf{S}$ & $\mathbf{M o}$ & $\mathbf{C r}$ & $\mathbf{N i}$ & $\mathbf{A l}$ \\
\hline $\begin{array}{c}\text { Percentage } \\
\text { (By Wts.) }\end{array}$ & 86.4. & 0.608 & 0.563 & 0.0449 & 0.849 & 0.0309 & 0.149 & 1.14 & 0.318 & 0.0338 \\
\hline
\end{tabular}

\subsection{Experimental Setup}

The machining operation on EN31was carried out on a Vertical Milling Machine available in Mechanical Deptt Lab NITTTR Chandigarh and shown in Figure. 1 


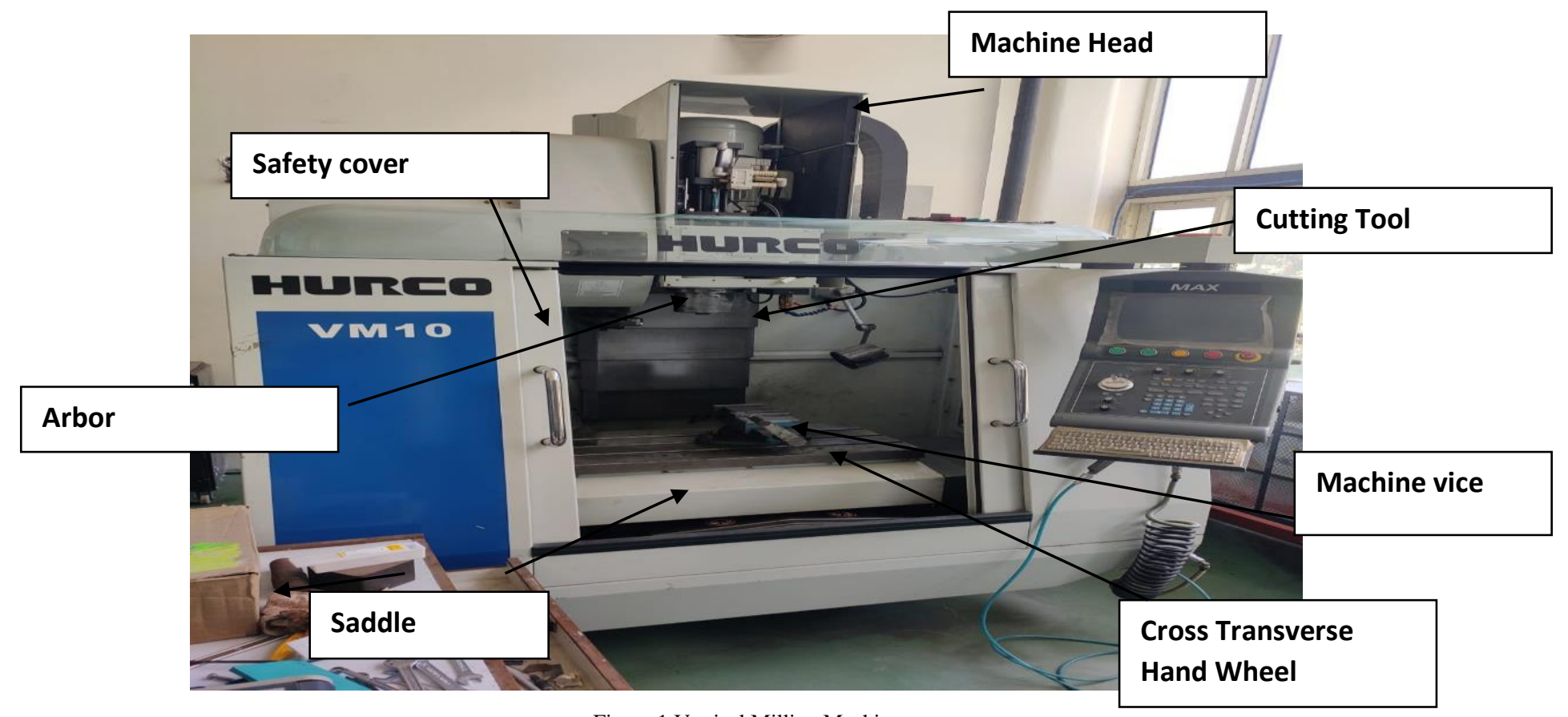

Figure 1.Vertical Milling Machine

The factors and levels selected for the machining of steel alloy are shown in Table 2.

Table 2. Process Parameters \& their Levels

\begin{tabular}{cccccc}
\hline Symbol & Input Parameter & Unit & \multicolumn{3}{c}{ Levels } \\
\cline { 4 - 6 } & & & 1 & 2 & 3 \\
& & & $(-1)$ & $(0)$ & $(+1)$ \\
\cline { 3 - 6 } S & Spindle Speed & Rpm & 600 & 800 & 1000 \\
F & Feed Rate & $\mathrm{mm} / \mathrm{min}$ & 50 & 100 & 150 \\
D & Depth of Cut & $\mathrm{mm}$ & 0.5 & 1.0 & 1.5 \\
\hline
\end{tabular}

Millingoperations werecarried out as per L9 orthogonal using Taguchi design.

\section{Measurements}

The surface roughness( $\mathrm{Ra})$ of each workpiece is checked by the surfaces roughness tester shown in figure 2 (MITUTOYO make), which is available at NITTTR Chandigarh. Surface roughness is measured in 3 trials and their average value is taken for the result . 


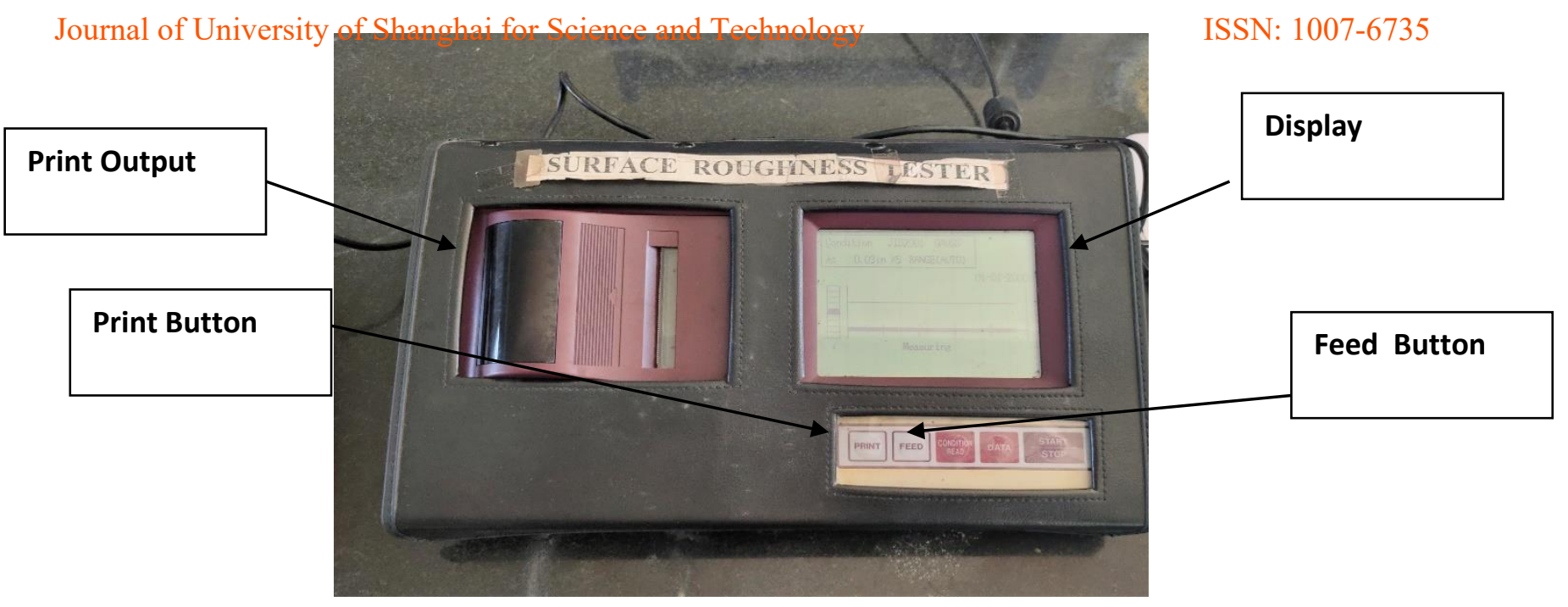

Figure 2. Surface Roughness Tester

Material removal rate and tool wear rate of each workpiece are obtained by dividing the difference of initial weight and weight after machining by machining time.

\section{Results}

The outcomes achieved after machining of EN31 workpieces were analyzed and optimized using different techniques as discussed in this section.

\subsection{Taguchi Optimization}

The results obtained after machining of EN31 by using input process parameters combinations as per the L9 Taguchi design are given in Table 3.

Table 3. Responses \& S/N Ratios

\begin{tabular}{|c|c|c|c|c|c|c|c|}
\hline $\begin{array}{c}\text { Speed } \\
(\mathrm{rpm})\end{array}$ & $\begin{array}{c}\text { Feed } \\
(\mathrm{mm} / \mathrm{min})\end{array}$ & $\begin{array}{c}\text { DOC } \\
(\mathrm{mm})\end{array}$ & $\begin{array}{c}\text { SR } \\
(\mu \mathrm{m})\end{array}$ & $\begin{array}{c}\text { MRR } \\
(\mathrm{mm} 3 / \mathrm{Sec})\end{array}$ & $\begin{array}{c}\text { TWR } \\
(\mathrm{mm} 3 / \mathrm{Sec})\end{array}$ & SNRA1 & SNRA2 \\
\hline 600 & 50 & 0.5 & 5.4 & 2.42 & .103 & $\mathbf{- 1 4 . 6 4 8}$ & 7.67631 \\
\hline 600 & 100 & 1 & 7.19 & 6.63 & .127 & -17.135 & 16.4303 \\
\hline 600 & 150 & 1.5 & 7.21 & 8.21 & .151 & -17.159 & 18.2869 \\
\hline 800 & 50 & 1 & 6.2 & 5.26 & .138 & -15.848 & 14.4197 \\
\hline 800 & 100 & 1.5 & 8.46 & 7.98 & .161 & -18.547 & 18.0401 \\
\hline 800 & 150 & 0.5 & 6.45 & 3.19 & .182 & -16.191 & 10.0758 \\
\hline 1000 & 50 & 1.5 & 6.79 & 8.43 & .145 & -16.637 & $\mathbf{1 8 . 5 1 6 6}$ \\
\hline 1000 & 100 & 0.5 & 7.43 & 3.42 & .176 & -17.42 & 10.6805 \\
\hline 1000 & 150 & 1 & 8.23 & 6.52 & .197 & -18.308 & 16.285 \\
\hline
\end{tabular}

In the Taguchi method, the level at which the value of the $\mathrm{S} / \mathrm{N}$ ratio is higher, the stability will be higher. This will select factor levels with the highest SNR for respective factors. Whatever the requirement is Smaller-the-Better or Larger-the-Better, a higher SNR will result in the smallest deviation. Thus, the parameter with a higher SNR will produce an optimum value and a negligible noise/variance. The observed/experimental value for surface roughness (Ra) is $5.4 \mu-\mathrm{m}$ and the corresponding SNR value is -14.648 . For material removal rate (MRR) is $8.43 \mathrm{~mm} 3 / \mathrm{sec}$ and the corresponding SNR value is 18.5166 .

A more in-depth analysis is done by using ANOVA which outlines the contribution of each parameter/factor

\subsubsection{Analysis of S/N Ratio}

The contribution of the responses may be found in Table 4 . 


\begin{tabular}{|c|r|c|r|r|r|r|} 
& \multicolumn{2}{|c|}{$\begin{array}{c}\text { Surface Roughness(SR) } \\
\text { (Smaller is better) }\end{array}$} & \multicolumn{3}{|c|}{$\begin{array}{c}\text { Material Removal Rate (MRR) } \\
\text { (Larger is better) }\end{array}$} \\
\hline LEVEL & \multicolumn{1}{c|}{ Speed } & \multicolumn{1}{c|}{ Feed } & \multicolumn{1}{c|}{ DOC } & \multicolumn{1}{c|}{ Speed } & \multicolumn{1}{c|}{ Feed } & \multicolumn{1}{c|}{ DOC } \\
\hline $\mathbf{1}$ & -16.31 & -15.71 & -16.09 & 14.131 & 13.538 & 9.478 \\
\hline $\mathbf{2}$ & -16.86 & -17.70 & -17.10 & 14.179 & 15.050 & 15.712 \\
\hline $\mathbf{3}$ & -17.46 & -17.22 & -17.45 & 15.161 & 14.883 & 18.281 \\
\hline Delta & 1.14 & 1.99 & 1.36 & 1.030 & 1.513 & 8.804 \\
\hline Rank & 3 & 1 & 2 & 3 & 2 & 1 \\
\hline
\end{tabular}

For surface roughness, feedis the highest dominant factor followed by speed and DOC.For tool wear rate also, feed is the highest dominant factor. Whereas DOCaffects material removal rate the most.Figure 3 shows factorial effect plots for SNR of Ra and MRR. Thus it is clear from factorial plots that 'Ra'is minimized at parameters; $\mathrm{S}=600, \mathrm{~F}=50, \mathrm{DOC}=0.5$, Quality $=1$. The 'MRR' is maximized at $\mathrm{S}=1000, \mathrm{~F}=100, \mathrm{DOC}=1.5$.

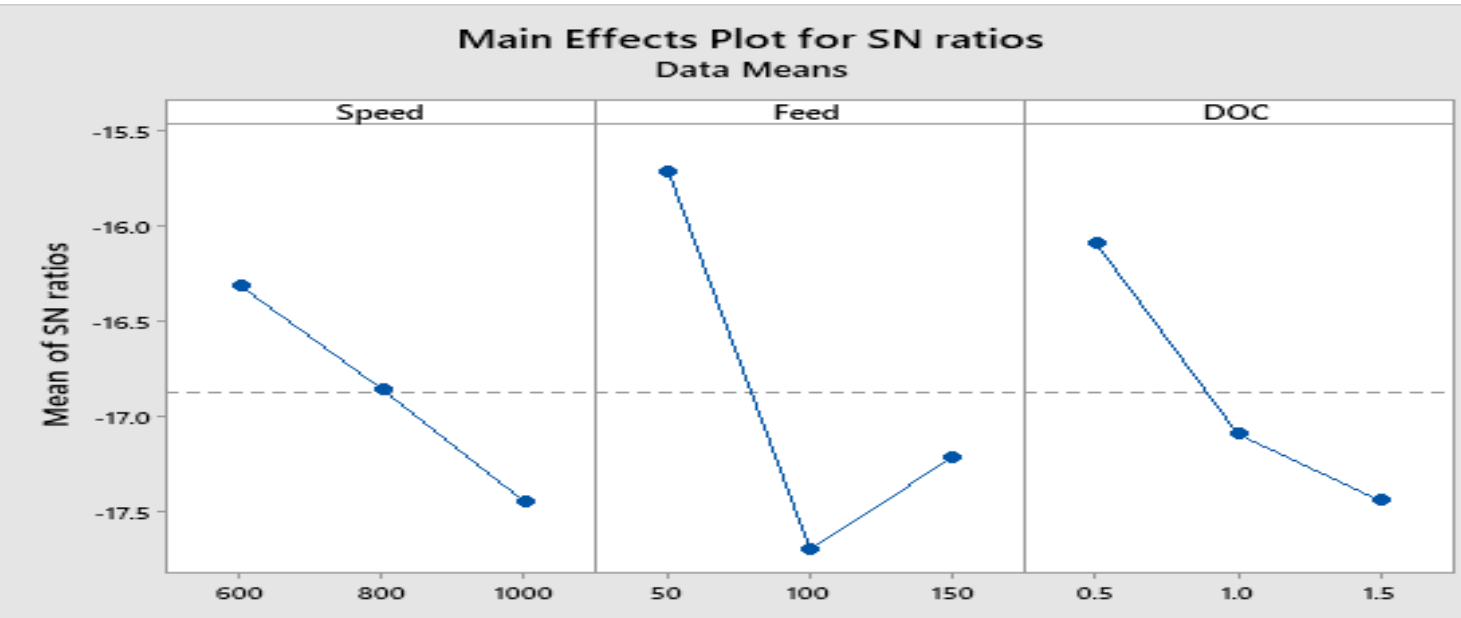

Signal-to-noise: Smaller is better

(a)

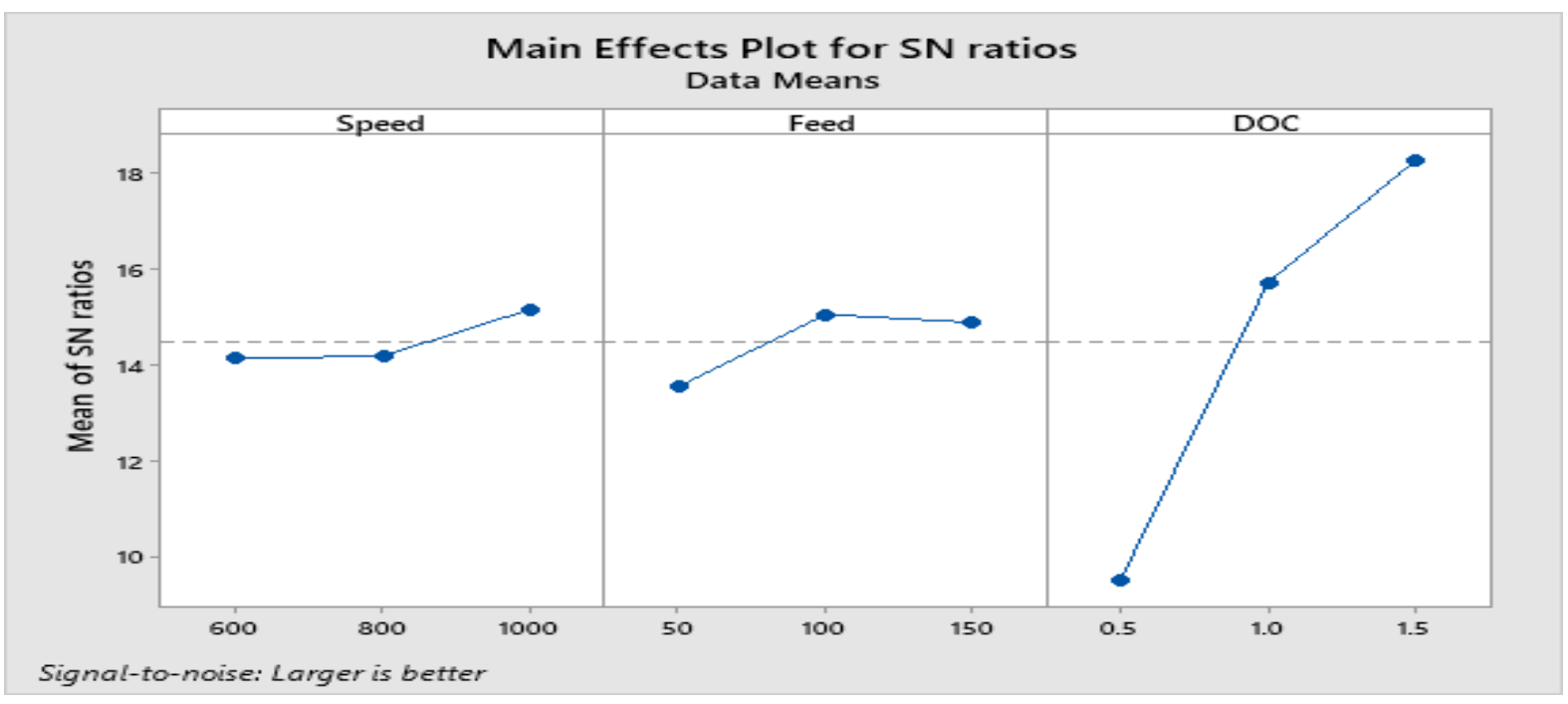

(b)

Figure. 3: Mean Effect Plots for (a) Surface Roughness (b) Material Removal Rate

\subsubsection{ANOVA}

The primary objective of ANOVA is to examine the effect of individual aspects and their interaction. The experimental study was conducted at $95 \%$ assurance zone and $5 \%$ significance zone. In table 4 . The value of $\mathrm{R}$ 
Journal of University of Shanghai for Science and Technology

ISSN: 1007-6735 Square explains the range where the input parameters intercept the change in the output response and the predicted variable. Like, for a better model, the $\mathrm{R}$ square would have to be larger of great value. The error in all responses is less than 5\%, so the performance is acceptable up to a higher level.

Table 4. ANOVA for Surface Roughness

\begin{tabular}{|l|c|c|c|c|c|}
\hline Source & DF & Adj SS & Adj MS & F-Value & P-Value \\
\hline Speed & 2 & 1.1705 & 0.5852 & 2.35 & 0.299 \\
\hline Feed & 2 & 3.9625 & 1.9812 & 7.95 & 0.112 \\
\hline DOC & 2 & 1.8104 & 0.9052 & 3.63 & 0.216 \\
\hline Error & 2 & 0.4985 & 0.2492 & & \\
\hline Total & 8 & 7.4418 & & & \\
\hline
\end{tabular}

Model Summary

\begin{tabular}{lrrr}
\multicolumn{1}{l}{$\mathbf{S}$} & R-sq & R-sq(adj) & R-sq(pred) \\
\hline 0.499233 & $95.30 \%$ & $73.21 \%$ & $0.00 \%$
\end{tabular}

\section{Regression Equation}

$S R=7.040-0.440$ Speed_600 -0.003 Speed_800 +0.443 Speed_1000 -0.910 Feed_50

+ 0.653 Feed_100 + 0.257 Feed_150 - 0.613 DOC_0.5 + 0.167 DOC_1.0 + 0.447 DOC_1.5

Table 5. ANOVA for Material Removal Rate

\begin{tabular}{|l|c|c|c|c|c|}
\hline Source & DF & Adj SS & Adj MS & F-Value & P-Value \\
\hline Speed & 2 & 0.6316 & 0.3158 & 1.57 & 0.389 \\
\hline Feed & 2 & 0.7750 & 0.3875 & 1.93 & 0.342 \\
\hline DOC & 2 & 41.0663 & 20.5331 & 102.12 & 0.010 \\
\hline Error & 2 & 0.4022 & 0.2011 & & \\
\hline Total & 8 & 42.8750 & & & \\
\hline
\end{tabular}

Model Summary

\begin{tabular}{rrrr} 
S & R-sq & R-sq(adj) & R-sq(pred) \\
\hline 0.448417 & $99.06 \%$ & $96.25 \%$ & $81.01 \%$
\end{tabular}

\section{Regression Equation}

MRR = $5.784-0.031$ Speed_600 -0.308 Speed_800 +0.339 Speed_1000 -0.414 Feed_50

+0.226 Feed_100 + 0.189 Feed_150 - 2.774 DOC_0.5 + 0.352 DOC_1.0 + 2.422 DOC_1.5 
As an optimal level is obtained from the curves and experimental data are gathered by machining. To achieve a meaningful outcome, responses are collected at the optimum expected level. As a result, the error is computed between the two readings.If the error is below 5\%, the optimum level achieved is acceptable until it is satisfactory. The confirmation is given in table 6 . Since the data obtained by a validation test for 'Ra' are inferior to the initial data obtained, this minimizes 'Ra'.Similarly, the value of "MRR" through the validation test is more than the initial value, therefore it also maximizes "MRR".

Table 6. Result for the confirmation test

\begin{tabular}{|c|c|c|c|c|c|}
\hline \multirow{2}{*}{$\begin{array}{c}\text { Response } \\
\text { Factor }\end{array}$} & Levels & \multirow{2}{*}{$\begin{array}{c}\text { Initial } \\
\text { Factor }\end{array}$} & \multicolumn{2}{|c|}{ Optimal process condition } & Error \\
\cline { 4 - 5 } & & & Prediction & Experimental & $(\boldsymbol{\%})$ \\
\hline SR & 111 & 5.4 & 111 & 5.4 & 0 \\
\hline MRR & 213 & 8.43 & 323 & 8.46 & 0.35 \\
\hline
\end{tabular}

\section{DISCUSSION}

This experimental study focus on Taguchi and ANOVA methodology and desirability function for investigating the effect of cutting parameters on Surface Roughness and Material Removal Rate in Vertical Milling Machining of EN31. The results obtained based onthe L9 orthogonal array for Taguchi and ANOVA approaches are summarized and compared in this section.

\section{Taguchi Design}

Taguchi design along with ANOVA optimizes output responses individually. The optimized response parameters and the corresponding cutting parameters are shown in Table

Table 7: Optimized Parameters Obtained by Taguchi Method

\begin{tabular}{|c|c|c|c|c|c|c|c|}
\hline \multicolumn{6}{|c|}{ Cutting Parameters } & \multicolumn{2}{|c|}{ Response Parameters } \\
\hline \multicolumn{2}{|c|}{ Speed (RPM) } & \multicolumn{2}{|c|}{ Feed $(\mathrm{mm} / \mathrm{min})$} & \multicolumn{2}{|c|}{ Depth of Cut (mm) } & \multirow{2}{*}{$\begin{array}{c}\text { SR } \\
(\mu \mathbf{m})\end{array}$} & \multirow{2}{*}{$\begin{array}{c}\text { MRR } \\
(\mathrm{mm} 3 / \mathrm{sec})\end{array}$} \\
\hline VALUE & RANK & VALUE & RANK & VALUE & RANK & & \\
\hline 600 & 3 & 50 & 1 & 0.5 & 2 & 5.4 & ----- \\
\hline 800 & 3 & 50 & 2 & 1.5 & 1 & ----- & 8.43 \\
\hline
\end{tabular}

The same set of cutting parameters was obtained for minimized surface roughness and tool wear rate by Taguchi design, whereas a different set of parameters was achieved for maximizing Material Removal Rate. Analysis showed that feed rate is the most important factor for Surface Roughness. However, the second most important factors for surface roughness were speed and DOC respectively. For DOC is the highest significant parameter for Material Removal Rate followed by speed and feed.

\section{Conclusions}

The experimental investigation of EN31machining with Vertical Milling Machine was carried out with the Taguchi, \&ANOVA techniques. The study considered three output variables, such as surface roughness, MRR and TWR and linear regression models have been developed for predicting these variables. Surface roughness value decreases with increase in cutting speed and increases with increase in depth of cut. Material removal rate (MRR) value increases drastically with increase in feed and depth of cut. Tool wear rate (TWR) value increases drastically with increase in feed and depth of cut. For the validation of results, four additional set of experiments have been performed and the results are in agreement with predictive models within $\pm 15 \%$ and hence the predictive models are validated and can be used for selecting input variables for required values of output variables.Conclusions are as follows. When machining of EN31, the most important factor for surface roughness is the feed followed by the speed of the spindle and the least important is DOC. When machining EN31, the most important factor for material removal rateis the DOC followed by the speed of the spindle and the least important is feed. From Taguchi method optimum factor levels for surface roughness as speed $=600 \mathrm{rpm}$, feed $=50 \mathrm{~mm} / \mathrm{min}$ and DOC $=0.5 \mathrm{~mm}$. For material removal rate the optimum factor levels as speed $=800 \mathrm{rpm}$, feed $=50 \mathrm{~mm} / \mathrm{min}$ and $\mathrm{DOC}=1.5 \mathrm{~mm}$ 


\section{References}

1. Deepak, D. and Beedu, R., 2017, August. Multi response optimization of process parameters using grey relational analysis for turning of Al-6061. In IOP Conf. Ser. Mater. Sci. Eng (Vol. 225, p. 012092).

2. Kaladhar, M., Subbaiah, K.V., Rao, C. and Rao, K.N., 2011. Application of Taguchi approach and Utility Concept in solving the Multi-objective Problem when turning AISI 202 Austenitic Stainless Steel. Journal of Engineering Science \& Technology Miniew, 4(1).

3. Campatelli, G., Lorenzini, L. and Scippa, A., 2014. Optimization of process parameters using a response surface method for minimizing power consumption in the milling of carbon steel. Journal of cleaner production, 66, pp.309-316.

4. Vasudevan, H., Deshpande, N.C. and Rajguru, R.R., 2014. Grey fuzzy multiobjective optimization of process parameters for CNC turning of GFRP/Epoxy composites. Procedia Engineering, 97, pp.85-94.

5. Patole, P.B. and Kulkarni, V.V., 2018. Prediction of surface roughness and cutting force under MQL turning of AISI 4340 with nano fluid by using response surface methodology. Manufacturing Miniew, 5, p.5.

6. Jaiganesh, V., Yokesh Kumar, B., Sevvel, P. and Balaji, A.J., 2018. Optimization of process parameters on commercial mild steel using Taguchi technique. International Journal of Engineering \& Technology, 7(11), pp.138-142.

7. Raju, M.V. and Gedela, S.K., 2016. Experimental Investigation of Machining Parameters of CNC Milling for Aluminum Alloys 6063 and A380. International Journal of Engineering and Management Research (IJEMR), 6(1), pp.185-197.

8. Lee, Y., Resiga, A., Yi, S. and Wern, C., 2020. The Optimization of Machining Parameters for Milling Operations by Using the Nelder-Mead Simplex Method. Journal of Manufacturing and Materials Processing, 4(3), p.66.

9. Azuddin, M. and Abdullah, W., 2009. A Study on surface roughness and burr formation of Al6061 with different spindle speed and federate for small end milling cutter. International Journal of Integrated Engineering, 1(1), pp.1-7.

10. Antony, J., 2000. Multi-response optimization in industrial experiments using Taguchi's quality loss function and principal component analysis. Quality and reliability engineering international, 16(1), pp.3-8.

11. Faisal, N., \& Kumar, K. (2018). Optimization of machine process parameters in EDM for EN31 using evolutionary optimization techniques. Technologies, vol. 6(2), pp. 54.

12. Ahilan, C., Kumanan, S. and Sivakumaran, N., 2010. Application of grey based Taguchi method in multiresponse optimization of turning process. Advances in production Engineering \& management, 5(3), pp.171-180.

13. Sivam, SP Sundar Singh, SathiyaMoorthyKaruppaiah, BhaskarKarthikYedida, Jai Ram Atluri, and ShubhangMathur. "Multi response optimization of setting input variables for getting better product quality in machining of magnesium AM60 by grey relation analysis and ANOVA." PeriodicaPolytechnica Mechanical Engineering 62, no. 2 (2018): 118-125.

14. Chaudhari, M.M.M., Design of Experimentation of CNC Flame Cutting Machine Parameter's by Taguchi \& ANOVA Method.

15. Ali, R.A., Mia, M., Khan, A.M., Chen, W., Gupta, M.K. and Pruncu, C.I., 2019. Multi-response optimization of face milling performance considering tool path strategies in machining of $\mathrm{Al}$ 2024. Materials, 12(7), p.1013.

16. Ramanathan, R., Abuthahir, S.S. and Ranjithkumar, D.P., 2015. Analysis of CNC milling parameters for aluminum aa6063 by using Taguchi design. International Journal of Advanced Research in Biology, Ecology, Science and Technology (IJARBEST) Vol, 1.

17. Seo, Y. W., Ramulu, M., \& Kim, D.). "Machinability of titanium alloy (Ti'6Al'4V) by abrasive waterjets". Proceedings of the Institution of Mechanical Engineers, Part B: Journal of Engineering Manufacture, vol. 217(12), 2003 pp. 1709-1721.

18. Pandey, S., Kant, S., Mishra, V., Khatri, N., \&Ramagopal, S. V. (2013). Parametric optimization of ball end magneto rheological finishing process on EN-31. Int J ReceTechnolEng, vol. 2(2), pp. 2277-3878.

19. Shah, C.D., Mevada, J.R. and Khatri, B.C., 2013. Optimization of process parameter of wire electrical discharge machine by response surface methodology on Inconel-600. International Journal of Emerging Technology and Advanced Engineering, 3(4), pp.2250-2459.

20. Srivastava, V. S., Srivastava, A. K., Singh, S. K., Nag, A., \& Patel, R. V. Effect of Process Parameter on diametric deviation during CNC lathe turning of EN-31 Steel. International Journal of Advance Research in Science and Engineering, vol. 6(2), pp. 600-606. 
Journal of University of Shanghai for Science and Technology

ISSN: 1007-6735

21. Prajapati, N.K. and Patel, S.M., 2013. Optimization of process parameters for surface roughness and material removal rate for SS 316 on CNC turning machine. International Journal of Research in Modern Engineering and Emerging Technology, 1(3), pp.40-47.

22. Elatharasan, G. and Kumar, V.S., 2013. An experimental analysis and optimization of process parameter on friction stir welding of AA 6061-T6 aluminum alloy using RSM. Procedia Engineering, 64, pp.1227-1234.

23. Sukumar, M.S., Ramaiah, P.V. and Nagarjuna, A., 2014. Optimization and prediction of parameters in face milling of Al-6061 using Taguchi and ANN approach. Procedia Engineering, 97, pp.365-371.

24. Devkumar, V., Sreedhar, E. and Prabakaran, M.P., 2015. Optimization of machining parameters on AL 6061 alloy using response surface methodology. International Journal of Applied Research, 1(7), pp.01-04.

25. Mumtaz Rizwee \&Dr. P. Sudhakar Rao, 2021, Analysis \& Optimization of Parameters during EDM of Aluminium Metal Matrix Composite, Journal of University of Shanghai for Science and Technology pp.218-223.

26. Abhisheik Thakur, Younis Khan \&Dr. P. Sudhakar Rao, 2021, Study and optimization of surface roughness parameter during electrical discharge machining of titanium alloy, International Journal of Innovative Technology and Exploring Engineering ,(Ti-6246)pp.203-212

27. Dr P. SudhakarRao,P.K.Jain \& D.K.Dwivedi,2016, Optimization of Key Process Parameters on Electro Chemical Honing (ECH) of External Cylindrical Surfaces of Titanium alloy Ti 6AI 4V, International Journal Of Technical Innovation In Modern Engineering \& Science (IJTIMES), pp 312-342pp2279-2289

28. Nishant Verma, S C Vettivel,Dr P.S Rao and Sunny Zafar,2019,Processing, tool wear measurement using machine vision system and optimization of machining parameters of boron carbide and rice husk ash reinforced AA 7075 hybrid composite, International Journal of Innovative Technology and Exploring Engineering, pp212-221

29. Rahul Bansal, Dr .P Sudhakar Rao, Amritbir Singh, 2019. Optimization Of Machining Parameters Of Electrochemical Machiining-A Review, International Journal Of Technical Innovation In Modern Engineering \& Science (IJTIMES), pp 312-342

30. Nishant Kumar, P. Sudhakar Rao,2020,Analysis And Optimization Of Process Parameters During Electric Discharge Machining Of Incoloy 800: A Review International Journal Of Scientific \& Technology Research Volume 9, Issue 02, February 2020, Pp.6002-6012

31. Shweta Verma \& P. Sudhakar Rao ,2019, Design And Analysis Of Process Parameters On Multistage Wire Drawing Process-A Review, International Journal of Mechanical and Production Engineering Research and Development (IJMPERD),pp 512-523

32. Chandan Mattu, Dr. P. Sudhakar Rao,2018,A Review Of Wear Characterization And Fabrication Of Aluminium Matrix Composites, International Journal Of Technical Innovation In Modern Engineering \& Science (ljtimes),Pp475-482

33. Shipra Verma, P.Sudhakar Rao,2018,Study on Mechanical Behavior of Aluminum Alloy 6061 Based Composites a Review, IOSR Journal of Mechanical and Civil Engineering (IOSRJMCE),pp16-20 